\title{
Breathing Life into the Syllabus: The Collaborative Development of a First-Year Writing Course for Nursing Students
}

Mark Feltham and Mary Anne Krahn Fanshawe College

In this essay, we tell the story of how a team of English and nursing professors came together to develop curriculum for a mandatory first-semester writing course in the collaborative Bachelor of Science, Nursing (BScN) at Fanshawe College and Western University, both in London, Ontario. The discussion focuses on the implementation of the course at the Fanshawe site. Following a review of literature that has informed our thinking about writing in nursing, we discuss how the team, consisting of both English/writing and nursing faculty, solved curriculum problems to develop an effective course. We also look forward to areas for future development.

\section{Introduction}

$\mathrm{T}$ This essay tells the story of how a team of English and nursing professors came together to develop curriculum for a mandatory first-semester writing course in the collaborative Bachelor of Science, Nursing $(\mathrm{BScN})$ at Fanshawe College (hereafter Fanshawe) and Western University (hereafter Western). The need to build this course resulted in ongoing discussions among educators of very different disciplinary backgrounds about topics ranging from the basic mission of the course to the development of discipline-relevant assignments. Our reflections on this process will likely interest educators seeking to develop a similar course; however, these reflections also raise larger questions regarding students' needs, interdisciplinary and crossinstitutional collaboration, and curriculum development processes.

\section{Why do nurses need writing skills and what writing skills should we teach them?}

The process of developing this course began with a research project, approved by the Research Ethics Boards of both Fanshawe College and Western University and supported by both institutions, designed to assess the writing skills of first-year nursing students. Although a full discussion of this study is beyond the scope of this essay, the findings did support what we already knew both intuitively and anecdotally: first-year nursing students had gaps in their writing skills. In addition, the review of the literature regarding nursing students and writing skills undertaken for this study informed our initial thinking about the course. This literature revealed almost universal recognition of writing as a crucial professional skill. We were assisted in this regard by 
relatively recent work (Andre \& Graves, 2013) surveying writing teaching in nursing programs at Canadian colleges and universities: this article, along with our own parallel database searches, showed decades-old patterns in the literature (in English) regarding nurses and writing.

Several common threads quickly emerged. Most importantly, nurses need writing skills because, simply put, nurses write. For example, Troxler, Jacobson Vann, and Oermann's (2011) statement that $"[\mathrm{w}]$ ritten communication skills are critical for nursing practice" (p. 280) reflects general scholarly consensus on this point (Andre \& Graves, 2013; Smith \& Caplin, 2012; Zygmont \& Schaefer, 2006; Zorn, Clark, \& Weimholt, 1997). In surveying this consensus, Andre and Graves (2013) thus concluded that "nursing programs have an obligation to ensure that nursing students are taught how to write well" (p. 91). Writing and related skills, moreover, as Andre and Graves (2013) further noted, fit into the larger context of what Smith and Caplin (2012) term "professional literacy," a key requirement of nursing practice involving the "ability to seek and apply skills related to scholarship for career advancement" (p. 121). In other words, professional programs should teach the professional skills required in professional practice. Despite the compelling logic of this line of argument, however, Andre and Graves (2013) also noted a relative lack of research on the role of writing courses in nursing curricula; what research does exist frequently addresses contexts other than Canada. Although their survey of writing-course requirements at Canadian Schools of Nursing has begun to fill this gap, more research is needed, especially with regard to how writing courses fit into the curriculum and what goes on within the classrooms themselves at the level of pedagogy. However, as Andre and Graves (2013) found, and so far as our own database searches can ascertain, there is not a deep body of literature addressing either the Canadian context with regard to writing instruction in nursing or the curriculum of a first-semester writing course in a nursing program.

Fortunately, we discovered that there are accounts of the kinds of writing tasks in which nurses engage, and our thinking about how to translate the general idea of a writing course into actual assignments and classroom practices began with this key question: what kinds of writing do nurses do? To name a few specific writing tasks, nurses "document patient care, communicate via writing with each other and colleagues in other disciplines, create educational materials for patients and staff, develop organizational policies and procedures, and compose material for publication" (Troxler, Jacobson Vann, \& Oermann, 2011, p. 280). This last point, moreover, speaks to an increasing stress on scholarly skills and activity within the nursing profession. Citing Riley, Beal, Levi, and McCausland (2002) and their articulation of the importance of nursing scholarship within the nursing profession, Andre and Graves (2013) elaborate on this point in relation to the necessary goals of writing courses for nurses, which

take on increased importance because they provide opportunities for students to learn how to locate, interpret, and evaluate relevant sources on a question; summarize, synthesize, and critique research findings; and pursue lines of inquiry leading to their own research papers. In other words, when nursing scholarship is reconceived as part of the professional role for all nurses, nursing students must learn not only how to be competent nurses but also how to become competent writers and researchers capable of contributing to the scholarship in their field. (pp. 92-93)

Professional and regulatory bodies also emphasize these same skills: the Canadian Association of Schools of Nursing (CASN) identifies critical thinking skills and "the ability to compose a written academic argument" (CASN, 2015, p. 12) as essential components of baccalaureate nursing education. The College of Nurses of Ontario (CNO), the governing body for nurses in Ontario, requires entry-level nurses to demonstrate competence in critical inquiry to inform clinical decision-making, the provision of nursing care, and evidence-informed documentation of assessments (CNO, 2014). In addition, any attempt to teach scholarly writing requires attention to a host of other skills (Zorn et al., 1997; Andre \& Graves, 2013): "format, style, and mechanics," 
including APA format (Gazza \& Hunker, 2012, p. 278), critical thinking (Borglin, 2012), and information literacy (Zorn et al., 1997).

These are skills that any writing student develops and refines over years of study and experience, and to expect a single 13-week writing course to address all of these areas in sufficient depth is unrealistic: course design must be selective. That said, however, the course does provide a foundation in all of these areas, including such overarching principles as critical thinking, grammar, and style, such nursing-specific areas as patient documentation, and such more-general-but-still crucial skills as information literacy, citation, and other aspects of scholarly writing. Before we describe the details of the course, however, we should briefly explain relevant details regarding the setting and the team of faculty members involved with the course.

\section{The teachers, the students, the course, and the setting: how nursing professors helped writing professors learn to teach writing to nursing students at Fanshawe College}

Both authors of this essay teach at Fanshawe College, one of the two sites that offer the course-the other site is Western University, the institution from which the students will ultimately receive their $\mathrm{BScN}$ degrees. Each site has approximately 125 students. The students at the Fanshawe site complete their first two years there, after which they transition to Western, joining the students who began at Western to create one graduating class. All students at both sites take the writing course in the first semester of their first year. As of Fall 2015, there were eight sections of the course at Fanshawe and five sections at the Western site.

The original syllabus from Western adapted an existing basic composition course at Western for the nursing program. In what follows, we confine our comments to specific pedagogical considerations to the course as offered at Fanshawe, as this site is where the authors teach. One of the authors (Feltham) has been the course leader at the Fanshawe site since the first offering of the course in fall 2012. At this site, the professors integrated nursing-relevant assignments within the general framework established by Western. This integration proceeded in several phases during the four offerings of the course that have occurred thus far.

The course begins with a short criticalresponse assignment on a health-care topic. Students then move on to an assignment addressing principles of health-care documentation. Next comes a sequence of assignments based on a research topic about a health-care scenario: students choose from a list of such scenarios. This sequence includes several assignments: a literature review, a short oral presentation, and a scholarly essay. It thus allows students to move through a clearly defined writing process integrating multiple elements associated with scholarly research and communication, including selecting and refining a topic, gathering information, presenting to colleagues, and writing up the results of the process. The course ends with a final exam. This exam is common to all sections at both Fanshawe and Western; the exact instructions for all other assignments, however, are specific to the site provided that they follow the general parameters established on the course outline.

Beginning in summer 2012, just prior to the first offering of the course, the team began to design the assignments for the course offerings at Fanshawe. Most of the assignments described above are standard elements in many general writing courses, regardless of their disciplinary focus: they addressed skills that the English professors had been teaching for years, albeit with a health-care dimension that seemed like new territory for some members of the teaching team. Fortunately, the team found it relatively easy to adapt experiences with similar types of assignments in other courses to this new offering. The documentation assignment, in contrast, looked like entirely unknown territory. Despite the potentially daunting gaps in teaching knowledge suggested by this assignment, the rest of the course aligned very well with the writing skills that figure prominently in the literature that we cite above. For example, critical thinking, analysis and 
synthesis, scholarly research and writing, and information gathering (to name several of the key areas that scholars have identified as crucial for nurses) were all easily addressed within the general course structure.

Before venturing into the unknown, the English professors started with what they knew. Because Fanshawe had an existing writing course addressing summary and critical thinking, with specific materials for pre-health science students, an existing assignment worked well (with some modifications) for the first assignment in the nursing course, but nothing extant was a viable option for the scholarly-essay sequence towards the end of the course. Thus, the team developed materials for this assignment in fall 2012, during the first offering of the course. In so doing, the team adopted the approach that John Bean (2011) advocates (along with many others): this sequence addresses openended, authentic scenarios that require the students to place themselves in the role of a nurse encountering a problem in actual clinical practice.

These scenarios are fairly open-ended and non-technical for several reasons. First, the openendedness was designed to require the students to narrow down their topics via the research and writing process, a standard feature of such assignments. Second, they are non-technical so that English professors could understand and grade them. There are several scenarios, ranging from more biomedical ones (infection control in a large, urban hospital and avoiding post-surgical re-admissions, for example) to psychosocial ones (ethics, patient confidentiality, and so on). This range allows students to pick scenarios based on a range that reflects the range of actual nursing practice. Standard course use of plagiarismchecking software allows re-use of the same assignment, and the course has used these scenarios, with some variation, in 2012, 2013, 2014, and 2015.

A particularly notable occasion for collaboration between writing course faculty and nursing faculty was the patient-notes assignment, which required considerably more disciplinary reorientation on the part of the English faculty. This assignment is the only one inherently specific to nursing: the other major assignments, though they address topics relevant to nursing, are standard types of writing assignments. Clearly, writing professors who have never worked as health professionals are not competent to teach students the technical details of charting procedures; thus, extensive discussions occurred about the role of the assignment within the course, and, in turn, the role of the course in the overall $\mathrm{BScN}$ curriculum. There were some false starts. For example, one early draft of the assignment was very biomedically focused and beyond the scope of the course. Because the assignment clearly cannot address the technical details of charting and nursing documentation, given the limits of the students' knowledge at the first-semester level and given that the course is taught by writing professors and not health professionals, early discussions regarding the assignment at Fanshawe revolved around this question: what general writing skills inform nursing documentation?

To answer this question, the writing professors asked for background information from the nursing faculty, reviewed this material, and then considered how to craft an assignment that would prepare students for more advanced instruction in documentation while not presuming to teach them its technical details. Fortunately, the material the nursing faculty provided was very helpful: of particular note were chapters on documentation in two of the students' nursing-course textbooks, Jensen's Nursing Fundamentals (Stephen, Skillen, Day, \& Jensen, 2012) and Potter and Perry's Canadian Fundamentals of Nursing (Potter, et al., 2014). Both textbooks are required for first-year classes in the $\mathrm{BScN}$ program, so students already have them. Both chapters emphasized the need for clarity, objectivity, and precision in documentation, and although writing professors are not competent to assess medical content, they can certainly deal with how these concepts relate to language use.

Once the discussion became firmly focused on the writing skills nurses use to document their interactions with patients in a clinical setting, the English professors on the team felt far more confident. Having learned some general principles governing health-care documentation, the English professors prepared sample patient notes that exemplified what the textbook chapters tell the students not to do with regard to documentation. 
Students then write an essay in which they set out the proper principles of patient documentation (using APA to cite their sources) and then apply these principles to the flawed notes. Finally, they re-write the notes (using some creativity) so that they illustrate, in general terms, the principles that they cite at the beginning. Grading focuses on how well the students demonstrate the writing skills that course addresses.

The overall goal of all of this work is a broader team approach drawing to a certain extent on "writing-across-the-curriculum initiatives in nursing education" (Andre \& Graves, 2013, p. 96), which

encouraged instructors to examine writing assignments and requirements at a programmatic level and to implement curricular changes designed to coordinate writing assignments across courses, to sequence assignments according to cognitive load, to incorporate more reflective writing and writing-to-learn activities, and to provide increased writing support for students. (Andre \& Graves, 2013, pp. 96-97)

The writing professors, all of whom work in the School of Language and Liberal Studies at Fanshawe, have worked very closely together in an effort to coordinate efforts among our different sections; in addition, meetings have included members of the nursing faculty for discussions that involved broader curriculum issues. One notable example involved bringing in a librarian to provide students with instruction about APA format (in addition to lessons on that topic in the writing classes) and the various library databases available to support research, topics relevant to both the writing course and several other nursing program courses in the same semester. One of these meetings revealed that the students were all together in one particular nursing program course, so rather than coming separately to each of the eight writing sections, the librarian came once to the common nursing course and provided the same information more efficiently to the entire group.

In addition, the assignments we describe above are sequenced "according to cognitive load" (Andre \& Graves, 2013, p. 97). Thus, course assignments begin with a controlled critical-response assignment that tests students' ability to analyze and critically respond to a short reading (using APA format); they then move to the patient-notes assignment, a longer and somewhat more complex assignment with increased demands involving broader source referencing and application of principles to a new context. Finally, they move up the ladder to the research sequence, which allows them to continue to develop and expand the skills from the opening assignments. All of these assignments, of course, are supported with ongoing lessons on such topics as critical thinking, evidence, a review of essay structure and the need to adapt this general structure to specific writing situations, principles of source referencing and APA format, library research, and relevant grammatical topics. As we have noted, this basic structure originated with Western; however, the actual execution of most day-to-day elements of the course at Fanshawe is the work of the professors there. One exception, we should note, is the final exam, which involves collaboration with the faculty at Western.

Finally, the course has room for reflective elements within the general emphasis on scholarly writing: the syllabus allows for $15 \%$ of the final grade to come from small assignments of the individual professor's own design, and these discretionary elements provide opportunities for reflection on various topics ranging from grammatical principles, citation conventions in scholarly writing, and any other topics the individual professor feels are appropriate to support learning.

\section{Border Crossings: what we learned and what we need to learn}

This account of how the course came to be illustrates several important principles of collaborative curriculum design. First and most importantly, it shows how everyone involved in disciplinary teaching ultimately found common ground. To do so, however, the English professors had to reach out to 
the nursing professors for help in finding resources that meshed with their own expertise and thus had to engage with the discourse of the discipline in question. Fortunately, nursing textbooks aimed at first-year students were perfect in this regard. Indeed, this experience was an excellent professional development opportunity for the English professors, as it allowed them to bridge between known concepts - for example, differences between objective and subjective writing-and hitherto unknown applications of these concepts to nursing documentation. The rest of the course did not require similar levels of research and disciplinary reorientation, as it involved more familiar types of assignments.

One key lesson in all of this, first and foremost, is the surprising amount of continuity between how nursing professors imagine writing and how English professors imagine it. When Andre and Graves (2013) note the importance of students learning "to locate, interpret, and evaluate relevant sources on a question; summarize, synthesize, and critique research findings; and pursue lines of inquiry leading to their own research papers" (pp. 92-93) in the context of nursing, they are describing a bridge that their own research has built between the worlds of English and writing studies and the world of nursing. Such continuity, however, often lies beneath a rather different-looking disciplinary surface, and considerable work can be required to reveal and map it.

That said, it would be a mistake to overstate this continuity. There are differences in how nurses approach writing. Many of these differences are questions of terminology: during conversations in the past year, it frequently emerged that although the team was mostly speaking the same language, different members spoke different disciplinary dialects of it. One minor but striking example turned up with regard to the final assignment sequence that we describe above: we had initially called this assignment a "research paper," but we changed this title to "scholarly essay" both to reflect the terminology in nursing and also to clarify that the assignment involves literature-based research rather than an actual empirical research study, a distinction that English professors might not readily make.
Also worth noting was a minor saga with regard to the teaching of APA format. Given that English primarily uses MLA rather than APA format (Andre \& Graves, 2013; Troxler, et al., 2011), the English professors (in some cases at least) found themselves discovering at least some of the intricacies of APA alongside the students. This citational border crossing was made easier because APA is part of many other English and communication courses at Fanshawe; however, the transition nonetheless provoked many interesting reflections on the underlying logic of citation systems and why different disciplines cite things as they do.

There is additional work to do. More work is necessary with regard to coordinating the course offerings between faculty at the Fanshawe and Western sites: as we note, Fanshawe faculty are using common assignments and, in many cases, common, collaboratively developed grading rubrics, so additional collaboration with faculty at both sites would be desirable. Effective collaboration requires ongoing efforts: the conversations and dialogue that we describe here need to continue. It is not enough to do it once. Although (at the time of this writing), nursing professors at Fanshawe are merely one floor up and one building over from the English professors, without ongoing dialogue and collaboration, they might as well be on the other side of the world.

\section{Conclusion: collaborating towards professional literacy}

Even a well-designed syllabus is, by definition, flat and lifeless: the true measure of a course is what happens as it unfolds in real time in the many and complex interactions among the professors, the course objectives, and the students. The course began as a fairly standard writing course with some nursingspecific elements, and we hope that this essay illuminates our efforts thus far to move from the pedagogically flat perspective of the course as it existed on paper to a robust, multi-section offering that effectively addresses the various points that we summarize above-in other words, how everyone involved has sought to breathe life into the syllabus. 
These curricular and collegial interactions again remind us of Smith and Caplin's (2012) term "professional literacy," which they define as a key requirement of nursing practice involving the "ability to seek and apply skills related to scholarship for career advancement" (p. 127). As English professors become a part of the development of writing, research, and critical-thinking skills for nursing students and thereby extend the thresholds of their own disciplinary expertise, they develop their own professional literacy as well.

\section{References}

Andre, J. D., \& Graves, R. (2013). Writing requirements across nursing programs in Canada. Journal of Nursing Education, 52(2), 91-97. https://dx.doi.org/10.3928/0148483 4-20130114-02 VIEW ITEM

Bean, J. C. (2011). Engaging ideas: The professor's guide to integrating writing, critical thinking, and active learning in the classroom ( $2^{\text {nd }}$ ed.). San Francisco, CA: Jossey-Bass.

Borglin, G. (2012). Promoting critical thinking and academic writing skills in nursing education. Nurse Education Today, 32, 611-613. https://dx.doi.org/10.1016/j.nedt.2011.06. 009 VIEW ITEM

Canadian Association of Schools of Nursing. (2015). National nursing education framework: Final report. Retrieved from http://www.casn.ca/w p-content/uploads/2014/12/Framwork-FIN AL-SB-Nov-30-20151.pdf VIEW ITEM

College of Nurses of Ontario. (2014). Competencies for entry-level Registered Nurse practice. Retrieved from http://www.cno.org/Global/ docs/reg/41037_EntryToPracitic_final.pdf VIEW ITEM

Gazza, E. A., \& Hunker, D. F. (2012). Facilitating scholarly writer development: The writing scaffold. Nursing Forum, 47(4), 278-285. https://dx.doi.org/10.1111/j.1744-6198.20 12.00275.x VIEW ITEM

Potter, P. A., Perry, A. G., Ross-Kerr, J. C., Wood, M. J., Astle, B. J., \& Duggleby, W. (Eds.). (2014). Canadian fundamentals of nursing ( $5^{\text {th }}$ ed.). Toronto, ON: Elsevier.

Riley, J. M., Beal, J., Levi, P., \& McCausland, M. P. (2002). Revisioning nursing scholarship. Journal of Nursing Scholarship, 34, 383-389.

Smith, Y. M., \& Caplin, M. (2012). Teaching the literacy of professionalism: When clinical skills are not enough. Nurse Educator, 37(3), 121-125. https://dx.doi.org/10.1097/NNE. 0b013e3182504188 VIEW ITEM

Stephen, T. C., Skillen, D. L., Day, R. A., \& Jensen, S. (2012). Canadian Jensen's nursing health assessment: A best practice approach. Philadelphia, PA: Lippincott Williams \& Wilkins.

Troxler, H., Jacobson Vann, J. C., \& Oermann, M. H. (2011). How baccalaureate nursing programs teach writing. Nursing Forum, 46(4), 280-288. https://dx.doi.org/10.1111/ j.1744-6198.2011.00242.x VIEW ITEM

Zorn, C. R., Clark, W. J., \& Weimholt, C. J. (1997). Educating the nurse scholar for the 21st century: How an interdisciplinary writing course can help. Journal of Nursing Education, 36(6), 244-249.

Zygmont, D. M., \& Schaefer, K. M. (2006). Writing across the nursing curriculum project. Annual Review of Nursing Education, 4, 275-290.

\section{Acknowledgements}

The authors thank Fanshawe and Western for their ongoing support of this course at both sites. In 
particular, we thank Dr. Carroll Iwasiw and Prof. Whitney Hoth, both of whom were investigators (with the authors) in the original research study that helped determine the need for the course. We thank Dr. Kathleen Fraser, Director of Writing at Western, for her efforts in designing the course. We also thank all Nursing professors who participated in meetings and consultations, including Professors and Program Coordinators Sharon Whitfield and Helen Harrison. Thanks must also go to Dr. Jamie Johnson, who has been the liaison between Fanshawe and Western faculty for this course. Special thanks must, of course, go to the professors who have taught the course at the Fanshawe site since 2012: Dr. Tom Barnes, Prof. Carmen Gindi, Prof. Whitney Hoth, Dr. Stephanie Ketley, Dr. Erin MacDonald, Dr. Sabine Milz, Dr. Amy Mitchell, Dr. Sharon Selby, and Prof. Kari Townsend. In addition, thanks are due to Prof. Paul Meahan and Dr. Jodi Hall, who read and commented on this essay during our revisions. Finally, and most importantly, we thank all the students who have taken WRIT-7004 at Fanshawe College.

\section{Biographies}

Dr. Mark Feltham, BA (Honours), MA, PhD, TESL (Ontario) is a professor of English and Communications in the School of Language and Liberal Studies at Fanshawe College in London, Ontario. His research focuses on writing pedagogy.

Mary Anne Krahn RN, BScN, MScN, is a Registered Nurse with a clinical background in paediatric nursing and a broad range of experience in nursing education. She is the Programs Chair in the School of Nursing at Fanshawe College in London, Ontario and a doctoral student in the Faculty of Education at Western University. 